\title{
Erratum to: TfR1 Extensively Regulates the Expression of Genes Associated with Ion Transport and Immunity
}

Nan HUANG ${ }^{1}$, Lei-lei ZHAN², Yi CHENG ${ }^{3}$, Xiao-long WANG ${ }^{1}$, Ya-Xun WEI ${ }^{2}$, Qi WANG ${ }^{2}$, Wen-jing LI $^{1}$

${ }^{1}$ Department of Allergy, Tongji Hospital, Tongji Medical College, Huazhong University of Science and Technology, Wuhan 430030, China

${ }^{2}$ Center for Genome Analysis, ABLife Inc., Wuhan 430075, China

${ }^{3}$ Department of Oncology, Tongji Hospital, Tongji Medical College, Huazhong University of Science and Technology, Wuhan 430030, China

(C) Huazhong University of Science and Technology 2020

\section{Current Medical Science}

https://link.springer.com/article/10.1007/s11596-020-2208-y

40(3):493-501,2020

It is hereby certified that there is no shared co-first authorship in this paper. Dr. Nan HUANG is the only first author of this article. 